\title{
Treatment of Experimental Allergic Neuritis With Prednisolone
}

\author{
T.E. Feasby, J.J. Gilbert, A.F. Hahn, D.S. Lovgren
}

\begin{abstract}
Experimental allergic neuritis (EAN) in Lewis rats was treated with prednisolone given prophylactically or therapeutically. Rats treated from the time of immunization with myelin or after the establishment of clinical disease improved more rapidly than controls. Treatment at the onset of clinical signs resulted in less severe disease and more rapid recovery. Rats treated just prior to the onset of clinical signs (day 10) did not develop significant clinical disease and appeared to have less inflammation in their nerves and nerve roots on microscopic examination.
\end{abstract}

RÉSUMÉ: Traitement de la névrite allergique d'origine expérimentale au moyen de la prednisolone Nous avons traité la névrite allergique d'origine expérimentale (NAE) chez des rats Lewis au moyen de la prednisolone administrée de façon prophylactique ou thérapeutique. Les rats qui étaient traités dès le moment de l'immunisation par la myéline ou après l'apparition de la symnptomatologie clinique se sont améliorés plus rapidement que les contrôles. La maladie était moins sévère et la guérison plus rapide chez les rats traités dès le début de signes cliniques ( 10 jours) n'ont pas développé des signes cliniques importants et semblaient avoir moins d'inflammation au niveau des nerfs et des racines nerveuses à l'examen microscopique.

Can. J. Neurol. Sci. 1987; 14:46-49

Corticosteroids have been widely used to treat the inflammatory-demyelinating neuropathies, Guillain-Barre Polyneuropathy (GBP)' and Chronic Inflammatory Demyelinating Polyneuropathy (CIDP). ${ }^{2}$ Steroids have also been reported to have both prophylactic and therapeutic effects on experimental allergic neuritis (EAN), ${ }^{3,4}$ the experimental model of GBP and CIDP.

We have re-examined the effect of prednisolone on the course of EAN in the Lewis rat.

\section{METHODS}

Myelin was extracted from bovine nerve roots by the method of Norton and Poduslo ${ }^{5}$ as modified by Kadlubowski et al. ${ }^{6}$ Male Lewis rats weighing $200 \mathrm{~g}$ were injected in the left hind foot pad with $5 \mathrm{mg}$ of myelin in saline plus Freund's complete adjuvant. The rats were graded daily on the following neurological clinical scale: 0-normal; 1-limp tail; 2-abnormal gait;3-moderate paraparesis; 4-paraplegia; 5-paraplegia with forelimb involvement and respiratory distress; 6-dead. ${ }^{7}$

The rats were divided into six groups of five and treated as shown in Table 1. Prednisolone (Sigma) was suspended in $0.9 \%$ saline to which 2 drops of Tween 80 had been added and was then injected i.p. at a dose of $10 \mathrm{mg} / \mathrm{kg}$.

The clinical scores were tested for significant differences using the Mann-Whitney $U$ test at a significance level of 0.05 .

\begin{tabular}{cccc}
\hline \multicolumn{2}{l}{ Table 1: Schedule for the Treatment of EAN with Prednisolone } \\
\hline \hline Group & $\begin{array}{c}\text { Immunized with } \\
\text { MBP + CFA }\end{array}$ & $\begin{array}{c}\text { Days of } \\
\text { Treatment }\end{array}$ & Treatment (i.p.) \\
\hline 1 & Day 0 & Day-1 to D25 & Prednisolone \\
2 & 0 & D10 to D25 & Prednisolone \\
3 & 0 & D13 to D25 & Prednisolone \\
4 & 0 & D16 to D25 & Prednisolone \\
5 & 0 & D-1 to D25 & Saline \\
6 & 0 & - & \\
\hline
\end{tabular}

On the 40th day after immunization, the rats were sacrificed with sodium pentobarbital and the lumbosacral nerve roots and the sciatic nerves were removed. Tissue was fixed in a solution of $6 \%$ mercuric chloride and $10 \%$ formaldehyde for two hours, then overnight in $10 \%$ formaldehyde, dehydrated in graded alcohols and embedded in paraffin. In samples from groups 2 and 5 , the amount of inflammatory infiltrate was assessed on an arbitrary scale of 0 to 4 , in 3 sections from each of 3 blocks from each tissue sample. All slides were coded and read "blind".

\section{RESUlts}

The clinical grades for all groups are shown in Figures $\mathbf{I}$ and 2. Control groups (group 5 [saline] and group 6 [no treatment]) showed a typical course of EAN with maximum severity about day 17 and gradual recovery thereafter. 

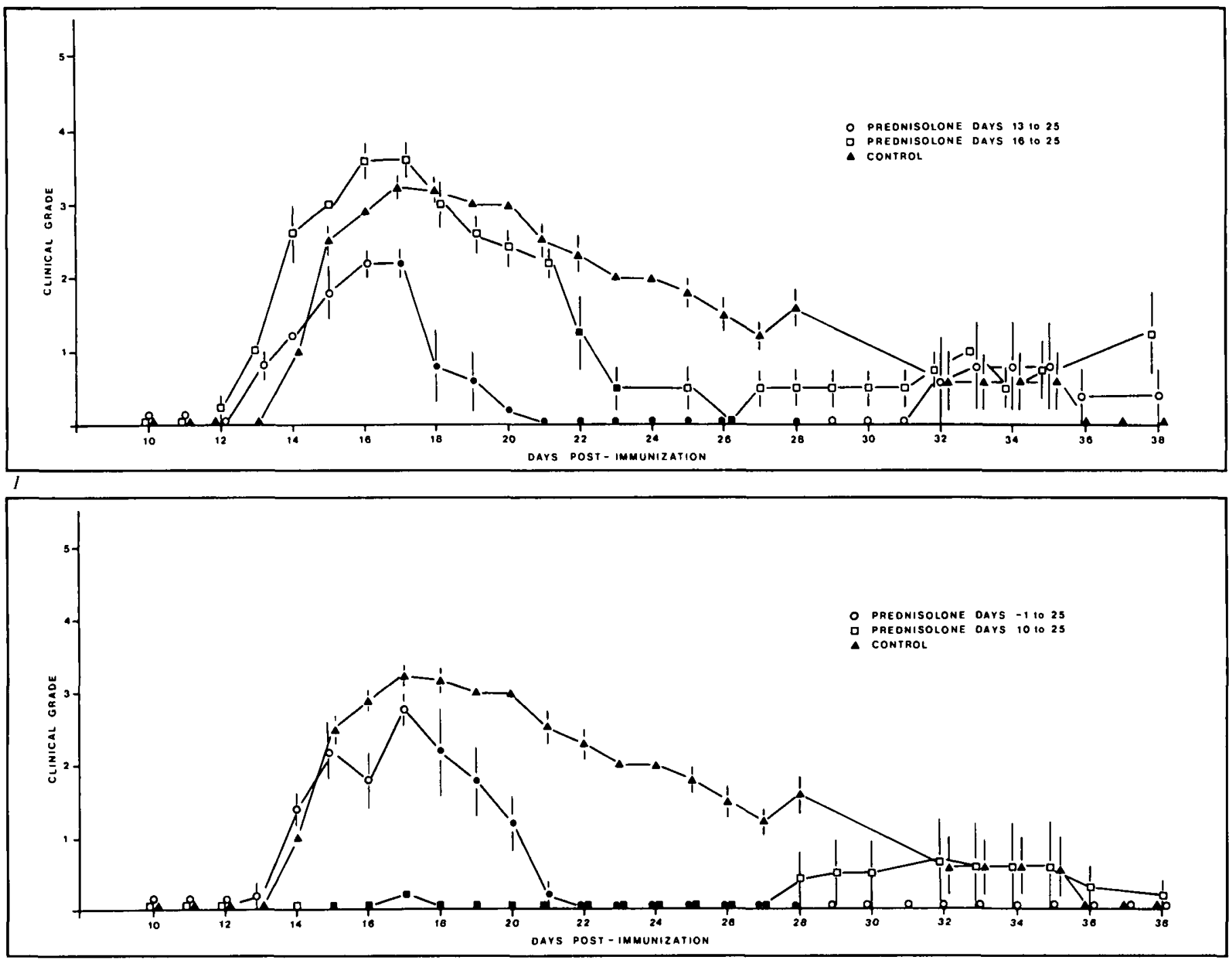

2

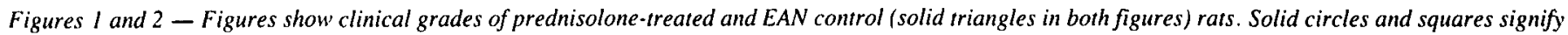
grades significanly different from control (triangles) grades. The control values (solid triangles) are the pooled results from the EAN groups treated with saline or untrealed (Groups 5 and 6).

The maximum severity of disease in Groups 1 (D-1 to D25) and 4 (D16 to D25) was not different from the controls (clinical grade $2.8 \pm 0.45$ and $3.6 \pm 0.25$ vs $3.25 \pm 0.16$ ). However, the time to recovery was shorter and the grade when prednisolone was withdrawn (day 25) was significantly lower than in controls $(p<.05)$. When rats were treated from the onset of symptoms (group 3, D13 to D25) there was a significant $(p<0.05$ ) reduction in the maximum severity of disease (clinical grade $2.2 \pm 0.2 \mathrm{vs}$ $3.25 \pm 0.16$ ). Additionally, afterfive days of treatment, the clinical scores in this group were not different from zero and the recovery time was significantly shorter than in the controls $(p<.05)$. Rats treated from days 10-25 (Group 2) did not show significant clinical signs of EAN throughout the course of the study (Figure 2), except for one rat which developed paraparesis on day 28 .

The amount of inflammatory infiltration of the nerve roots and sciatic nerves from group 2 and controls is shown in Table 2. Within each animal, there was a similar amount of inflammation in the roots and sciatic nerve. There was more inflammation in the nerves and roots of the control animals than in the prednisolone treated group; however, this difference was not statistically significant $(p=0.19)$. This corresponded to the more severe clinical disease in the control group.

\section{Discussion}

We have shown that prednisolone can significantly alter the course of Lewis rat EAN. The results seen when rats were

Table 2: Effect of Prednisolone on Inflammatory Infiltration and grade at sacrifice (day 40) in Lewis rat EAN

\begin{tabular}{lccc}
\hline \hline & Roots & Sciatic & Clinical Grade \\
\hline Control & + & + & 3 \\
& + & ++ & 3 \\
& ++ & + & 4 \\
& ++ & + & 3 \\
& + & ++ & 3 \\
Group 2 & ++ & 0 & 0 \\
(day 10-day 25) & + & ++ & 1 \\
& + & 0 & 0 \\
& 0 & 0 & 0 \\
& 0 & & 0 \\
\hline
\end{tabular}


treated either therapeutically (Group $3 \& 4$ ) or prophylactically (Group 1) correspond well with the observations of Hughes et $\mathrm{al}^{3}$ and King et al. ${ }^{4}$ In most cases there was just a slight reduction in maximum severity of disease but the time to recovery was reduced significantly. Thus, it seems that the main effect of prednisolone is to decrease the duration of disease. There is a report ${ }^{8}$ that prednisolone given at very high dosages $(7 \mathrm{mg} / \mathrm{kg}$ for 2 days) may reduce recovery time in certain inflammatory neuropathies in humans. This suggests that the lack of effect seen by other authors ${ }^{9}$ may be due to the much lower dosages usually administered to human patients. However, even in rats the effect of prednisolone was not particularly striking when given therapeutically.

The present study further examined steroid sensitive events in EAN by treating rats from before the onset of clinical symptoms (day 10). Clinical symptoms of EAN usually begin at days 12-13 but histological changes occur as early as day $8 .^{10}$ In this treatment group (Group 2) prednisolone completely blocked the expression of clinical signs. This suggests that the most steroid sensitive stages of EAN occur immediately before the onset of clinical symptoms. Even at day 40, there seemed to be less inflammation in nerves and roots from prednisolone-treated rats compared to controls. Prednisolone may have suppressed EAN by suppressing inflammation. Although it is unclear why prophylactic treatment (from day-1) was not as effective, there is some suggestion that the effects of corticosteroids decline with continued daily administration. 1

Prednisolone has been shown to affect a number of cell types involved in the inflammatory infiltrates in EAN. Macrophages both phagocytose myelin debris and actively strip away myelin lamellae, ${ }^{12}$ possibly via enzymatic mechanisms. ${ }^{13}$ It has been shown in vitro that, while phagocytosis is not affected, proliferative responses and secretion of proteinases are severely reduced by glucocorticoids. ${ }^{14}$ If macrophages are directly involved with demyelination, via the secretion of specific enzymes as suggested by Sobue et al, ${ }^{15}$ then the effects of glucocorticoids on the secretion of these enzymes could explain some of the reduction of symptoms seen with prednisolone treatment.

Recent reports suggest that glucocorticoids can have striking effects on certain T-cell subsets in rats and humans. Schuyler, et al $^{16}$ found that in rats, prednisone caused a non-selective depletion of all T-cell subclasses from the pool of circulating lymphocytes but did not affect the helper: suppressor ratio. In contrast, Hedman et al ${ }^{17}$ found that while the $\mathrm{T}$ and B-cells were reduced, there was a greater reduction in the subset defined by the $\mathrm{OX} 8$ antibody (suppressor/cytotoxic) than in the W/3/25-defined group (helper/inducer). In humans, steroids produce generalized lymphocytopenia but there is apparently a greater decrease in the helper subset (T4) than in the suppressor subset (T8), causing a decrease in the helper:suppresser ratio. ${ }^{18,19}$ Additionally, glucocorticoids probably inhibit activation ${ }^{20}$ and proliferative responses ${ }^{19}$ of T-cells. Since there is considerable evidence that Lewis rat EAN is T-cell mediated, ${ }^{21.22 .23 .24}$ steroids might be expected to modify the disease by their effects on T-cells.

Steroids have been used for many years to treat GuillainBarre Polyneuropathy (GBP), the human analogue of EAN, and there are many anecdotal reports of its effects (see Hughes). ${ }^{3}$ However, there are only two controlled studies of steroids in GBP and they yielded conflicting results. The first trial ${ }^{25}$ of 16 patients (excluding respirator-dependent patients) treated for
10 days with ACTH showed a reduced duration of illness but an increased length of hospitalization in the ACTH-treated group. Hughes et al ${ }^{19}$ compared 21 patients treated with prednisolone with 19 untreated patients, both groups including respiratordependent patients. The prednisolone group fared less well at each follow-up time to 12 months. This study suggests strongly that prednisolone is not effective therapy for GBP. In contrast to acute GBP, chronic inflammatory demyelinating polyneuropathy (CIDP) is responsive to steroids in many $\operatorname{cases}^{26.27}$ and is thus more like EAN in its response to steroids, than is acute GBP.

\section{ACKNOWLEDGEMENT}

Supported by the Muscular Dystrophy Association of Canada and the Medical Research Council of Canada.

\section{REFERENCES}

1. Arnason BG. Acute inflammatory demyelinating polyradiculopathies. In: Dyck P, Thomas P, Lambert E, Bunge R, eds. Peripheral Neuropathy, Philadelphia: W.B. Saunders Co. 1984; 2050-2100.

2. Dyck PJ, Arnason BG. Chronic inflammatory demyelinating Polyradiculoneuropathies. In: Dyck PK. Thomas P, Lambert E, Bunge R, eds. Peripheral Neuropathy, Philadelphia: W.B. Saunders Co. 1984; 2101-2114.

3. Hughes RAC, Kadlubowski M, Hufschmidt A. Treatment of Acute Inflammatory Polyneuropathy. Ann Neurol 9(Suppl) 1981; 125-133.

4. King RHM, Craggs RI, Gross MLP and Thomas PK. Effects of Glucocorticoids on Experimental Allergic Neuritis. Experimental Neurology 1985; 87: 9-19.

5. Norton WT, Poduslo SE. Myelination in rat brain-changes in myelin composition during brain maturation. J Neurochem (1973); 21 : 759-773.

6. Kadlubowski M, Hughes R, Gregson N. Experimental allergic neuritis in the Lewis rat-characterization of the activity of peripheral myelin and its major basic protein, P2. Brain Res 1980; 184 : 439-454.

7. Tansey F, Brosnan C. Protection against experimental allergic neuritis with silica quartz dust. J Neuroimmunol 1982;3: 168-179.

8. Dowling PC, Bosch VV, Cook SD. Possible beneficial effect of high-dose intravenous steroid therapy in acute demyelinating disease and transverse myelitis. Neurology 1980; 30: 33-36.

9. Hughes RAC, Newsom-Davis J, Perkin GD, Pierce JM. Controlled trial of prednisolone in acute polyneuropathy. Lancet 1978; 2 : 750-753.

10. Hahn AF, Feasby TE, Gilbert JJ. Blood-Nerve barrier studies in Experimental Allergic Neuritis. Acta Neuropathol (Berl) 1985; 68: $101-109$.

11. Rinehart JJ, Sagone AL, Balcerzak SP, Ackerman GA, LoBuglio AF. Effects of Corticosteroid Therapy on Human Monocyte Function. New England J Med 1975; 292: 236-241.

12. Lampert PW. Mechanism of Demyelination in Experimental Allergic Neuritis. Electron Microscope Studies. Lab Investigations 1969; 20: 127-138.

13. Cammer W, Bloom BR, Norton WT, Gordon AD. Degradation of basic protein in myelin by neutral proteases secreted by stimulated macrophages - a possible mechanism of inflammatory demyelination. Proc Nat Acad Sci (U.S.A.) 1978; 75: 1554-1558.

14. Werb Z. Biochemical actions of glucocorticoids on macrophages in culture. Specific Inhibition of Elastase, Collagenase, and Plasminogen Activator Secretion and effects on other metabolic functions. J Exp Med 1978; 147: 1695-1712.

15. Sobue G, Yamato S, Hirayama M, Matsuoka Y, Uematsu H, Sobue I. The role of macrophages in demyelination in experimental allergic neuritis. J Neurol Sc 1982; 56: 75-87.

16. Schuyler MR, Gerblich A, Vida C. Prednisone and T-Cell Subpopulations. Arch Int Med 1984; 144: 973-975.

17. Hedman LA, Rockert LL, Lundin PM. The effect of steroids on the circulating lymphocyte population VI: studies on the tho- 
racic duct $\mathrm{T}$ - and $\mathrm{B}$-lymphocyte populations alter neonatal thymectomy and prednisolone treatment. An immunofluorescence study in the rat. Int J Immunopharmacology 1984; 6: $357-363$.

18. Bast RC Jr, Reinherz EL, Maver C, Lavin P, Schlossman SF. Contrasting effects of cyclophosphamide and prednisolone on the phenotype of human peripheral blood leukocytes. Clinical Immunology and Immunopathology 1983; 28: 101-114.

19. ten Berge RJM, Sawerwein HP, Yong SL, Schellekens P'ThA. Administration of Prednisolone in vivo affects the ratio of OKT4/OKT8 and the LDH-enzyme pattern of Human T Lymphocytes. Clinical Immunology and Immunopathology 1984;30: 91-103.

20. Claman HN. Corticosteroids and lymphoid cells. New England J Med 1972; 287: 88-397.

21. Hughes RAC, Kadlubowski M, Gray IA, Leibowitz S. Immune responses in experimental allergic neuritis. J Neurology Neurosurgery and Psychiatry 1981b; 44: 565-569.

22. Linington $C$, Izumo S, Suzuki M, Uyemura K, Meyermann R, Wekerle $H$. A permanent rat-T-cell line that mediates experi- mental allergic neuritis in the Lewis rat in vivo. J Immunol 1984: 133: $1946-1950$.

23. Izumo S, Linington C, Wekerle $\mathrm{H}$ and Meyermann R. Morphologic Study on Experimental Allergic Neuritis Mediated by $\mathrm{T}$ Cell Line Specific for Bovine P2 protein in Lewis rats. Laboratory Investigation 1985; 53: 209-218.

24. Holmdahl R, Olsson T, Moran T, Klareskog L. In vivo Treatment of rats with monoclonal anti-T-cell antibodies. Immunohistochemical and functional analysis in normal rats and in experimental allergic neuritis. Scand J Immunol 1985; 22: 157-169.

25. Swick HM, McQuillen MP. The use of steroids in the treatment of idiopathic polyneuritis. Neurology (Minneop.) 1976;26: 205-212.

26. Dalakas MC, Engel WK. Chronic relapsing (dysimmune) polyneuropathy: pathogenesis and treatment. Ann Neurol 1981; 9 (Suppl): 134-145.

27. Dyck PJ et al. Prednisone improves chronic inflammatory demyelinating polyradiculoneuropathy more than no treatment. Ann Neurol 1982; 11: 136-141. 